\title{
Impact and Sustainability of a 10-year Community Pharmacy Disease Management Service
}

Tammy Lopez, PharmD ${ }^{1}$; Wesley Nuffer, PharmD ${ }^{2}$

${ }^{1}$ City Employee Pharmacy, Colorado Springs; ${ }^{1}$ Maxor National Pharmacy Services, LLC

${ }^{2}$ University of Colorado Skaggs School of Pharmacy \& Pharmaceutical Sciences

\section{ABSTRACT}

Background. Community pharmacy practice needs to demonstrate services beyond traditional dispensing roles to continue to function in a changing marketplace. Pharmacists have established themselves as being capable of improving patient outcomes and saving healthcare dollars by providing disease management services to patients. This paper describes a sustained community pharmacy-run disease management program that continued after a grassroots grant-funding effort in 2007.

Methods. The city of Colorado Springs recognized the successes shown by the pharmacy during the Ten City Challenge funded project, and decided to financially support pharmacy diabetes care services. Partnering with the local School of Pharmacy, the pharmacist obtained advanced training and continued to deliver individualized counseling and management to approximately 100 patients per year for the past 14 years. Objective lab measurements (systolic and diastolic blood pressures, A1C values, total lipid profiles) were obtained or performed, and clinical goals were set based on national guidelines. Patients received a series of appointments to learn how to control their diabetes, and later their cardiovascular disease. Financial estimates were calculated using 2008 baseline numbers and adding estimated inflation based on published Segal rates.

Results. The pharmacy services successfully maintained participation of approximately 100 patients annually each year since its inception. Average lab value markers for disease control were at or close to clinical guideline recommendations for the population. Services were associated with estimated cost savings for the health system. Positive results led to expansion in services to include cardiovascular disease in 2017.

Conclusions. A community pharmacy has successfully sustained a disease management program for patients for over 14 years, demonstrating high patient enrollment, health outcomes at or near clinical guidelines for control, and positive financial outcomes associated with the program.

Keywords: "community pharmacy", "disease management", "diabetes", "ten city challenge", "student pharmacists"

\section{BACKGROUND}

The profession of pharmacy continues to evolve in its role in contributing to patients' health. Pharmacists have demonstrated their ability to effectively educate and manage a spectrum of chronic diseases in both the health system and community practice settings. ${ }^{1-4}$ Student pharmacists are increasingly being trained to focus on patient outcomes, provide medication therapy management services, and work interprofessionally as part of their experiential training, also with documented successes. ${ }^{5-10}$ With traditional community pharmacy practice facing threats from decreased reimbursement rates and increasing direct and indirect remuneration (DIR) fees, it is important to continue to establish the pharmacist's role in direct patient care activities. ${ }^{11,12}$

In 2005, the American Pharmacists Association (APhA) Foundation partnered with GlaxoSmithKline specifically to expand on early models demonstrating pharmacists' ability to provide diabetes management to patients in the community

\section{Corresponding Author:}

Tammy Lopez, PharmD, BC-ADM, CDCES

Pharmacy Manager, Clinical Programs Coordinator, Clinical Pharmacist, City Employee Pharmacy

30 S. Nevada Ave, L04, Colorado Springs, CO 80903

P: 719-385-2261; F: 719-385-2264

Email: TLopez@maxor.com setting. ${ }^{13}$ Ten communities were selected across the United States to participate in this project, which ran for two consecutive years from January 2006 to December 2007. ${ }^{13}$ This project demonstrated decreased medical costs for participating employers and participants, and statistically significant improvements in clinical laboratory measures including hemoglobin A1C (A1C), low-density lipoprotein cholesterol (LDL-C), systolic and diastolic blood pressures, and patients' body mass index. ${ }^{13}$

At the conclusion of the project, one of the participating pharmacies, located in Colorado Springs, Colorado, was recognized for ranking in the top three performing cities based on project outcomes. The city of Colorado Springs recognized these successes and decided to continue to support these pharmacy-based services. This manuscript describes the sustainability and positive impact this pharmacy has made on the community served thirteen years after the original project ended.

\section{METHODS}

This retrospective review of patients' participation in pharmacy disease management services was designated Not Human Subject Research by the Colorado Institutional Review Board. The pharmacy providing these services is unique in that it serves only city employees and their dependents at one location that is closed to the general public. This allowed the pharmacist to forge relationships with patients and routinely 
interact with her clientele. Since the city elected to continue pharmacy diabetes services after the conclusion of the Ten City Challenge program in 2008, participants scheduled appointments and follow-ups with the delegated pharmacist in charge of the program. As an incentive to participate in the diabetes management program, the employer offered waived co-pays for all oral and injectable diabetes medications, diabetes supplies, insulin pumps and supplies, as well as generic blood pressure medications. Participants were eligible for these waived copay benefits as long as they actively participated in the program. Patients attended one-hour monthly management visits for the first three months of the program, were seen every two months for two additional visits, and then scheduled quarterly follow-up visits thereafter. Patients who did not maintain a minimum of quarterly diabetes appointments with the pharmacist became unenrolled from the program and their copay charges were reinstated. Laboratory measurements were routinely collected from either the patient's medical chart or performed utilizing point-of-care technology in the pharmacy, including A1C, cholesterol lipid profiles, blood pressure measurements, height, weight, and body mass index. The pharmacy tracked patients' pertinent medical histories including last dilated eye exam, last dental exam, last diabetes foot exam, last influenza vaccination, hepatitis $B$ and pneumococcal vaccinations in accordance to American Diabetes Association treatment guidelines.

\section{Pharmacist Training}

The pharmacist and clinical site coordinator initially received a certificate in diabetes care through APhA before beginning to manage patients. As the program continued upon completion of the grant-funded Ten City Challenge project, the pharmacist attained sufficient practice hours in diabetes management and successfully achieved her certified diabetes educator (CDE) certification, now titled certified diabetes care and education specialist (CDCES), through the Certification Board for Diabetes Care and Education (CBDCE). A few years later she applied for and received her board-certified advanced diabetes management (BC-ADM) certificate through the Association of Diabetes Care \& Education Specialists (ADCES). The pharmacist continuously identified areas to improve her knowledge, obtaining training from several companies as insulin pump devices and continuous glucose sensors entered the market and their utilization increased. Patients were able to get trained and managed on their insulin pumps.

The pharmacist contacted and partnered with the University of Colorado Skaggs School of Pharmacy shortly after beginning her role as the clinical site coordinator to gain support in documenting her patient encounters and to begin to receive student pharmacists to assist in the pharmacy clinical operations. Faculty from the school worked with the pharmacist continuously to help evolve, improve, and expand services as she continued to demonstrate successes on an annual basis.

\section{Diabetes Education Visits}

Patients newly enrolled into the diabetes program took an initial diabetes knowledge assessment test to determine their background knowledge around diabetes. The initial three monthly visits focused on building core skills for the patient by teaching them how to use and understand their glucose meter and blood pressure machine, briefly explaining the disease process of diabetes, and reviewing the importance of adherence. Patients would receive education around nutrition, maintaining an active lifestyle, managing stress, and would learn about the various diabetes treatments.

Visits four and five (held every two months) were structured to reinforce learning. Each patient would be asked to perform a blood glucose fingerstick, with the pharmacy team assessing technique and providing feedback. Patients would explain when they should test, what their target goal numbers should be, and how to manage fluctuations in their blood glucose, with an important focus on minimizing and controlling hypoglycemia. Patients would also demonstrate interpreting a food label, explain how different foods affected their blood glucose, and discuss what effects stress and physical activity had on their glucose levels. The pharmacy team members would look to identify any gaps in diabetes-related knowledge and reinforce key points during these sessions. Finally, the pharmacy team would ensure that each patient understood all of their diabetes-related medications, including when to take them and what to do if they missed a dose, and how to store these medications between uses. They also reiterated the importance of medication adherence and educated patients around proper foot care.

After completion of these core visits, patients transitioned to quarterly follow-up at the pharmacy. These on-going visits focused on the American Diabetes Association Standards of Care maintenance elements (dilated eye exams, microalbuminuria testing, annual foot exams, six-month dental exams, recommended immunizations). ${ }^{14}$ Patients would set various behavioral goals around meal planning, exercise, smoking cessation, and blood sugar testing and logging, and reported their success rates at subsequent visits, with an $80 \%$ achievement rate set as a cut point for success.

Laboratory measurements were performed utilizing point-ofcare technology for A1C values (DCA Vantage, Siemens, USA) or by retrieving recent blood tests performed by each patient's provider. New A1C values were collected on a quarterly basis as part of the diabetes program, so participants received this test four times per year. Each quarter these values were averaged across every participant in the program to yield a quarterly average A1C. Annually the four quarterly values were averaged to yield an annual average $\mathrm{A} 1 \mathrm{C}$ value.

Blood pressure measurements were performed at the pharmacy every visit, utilizing the Omron HEM-907XL 
automatic blood pressure monitor, with various cuff sizes to meet the needs of each patient. The frequency someone would receive a blood pressure depended on what visit they were on (visits 1-3 monthly, 4 and 5 every two months, and quarterly thereafter). Similar to the $\mathrm{A} 1 \mathrm{C}$ values, all systolic and diastolic blood pressure measurements were averaged on a quarterly basis to yield an average quarterly value, and those quarterly values were averaged to yield an annual blood pressure value. Lipid panels were obtained from chart records, where patients would receive fasting lipid panels once or twice a year, depending on their risk factors. These annual low-density lipoprotein-cholesterol (LDL-C) values were averaged for all patients in the program on an annual basis.

\section{Financial Estimates}

In order to provide feedback to leadership for the city of Colorado Springs, financial estimates were established each year of the program, based upon those performed during the Ten City Challenge. These estimates were broken down to cost per-member per-year. The goal was to provide an estimate of the medical and prescription drug costs of the average participants within the program. The year of the program's inception of 2008 after the grant ended served as the baseline cost for both prescription and medical costs. Estimated increases in these costs due to inflation were estimated utilizing the Segal inflation rates for prescription and medical costs, added each year onto this baseline. ${ }^{15}$ Actual patient costs were compared to these estimates to give a rough idea of any financial savings that occurred as a result of the pharmacy services. Of note, patients who exceeded $\$ 10,000$ in either prescription or medical costs for each year were considered "outliers" and were removed from these estimates. This accounted for approximately $20-25 \%$ of the program participants, varying each year. This was done because of the high impact these patients had on overall average costs. In 2019, for example, the five patients who were the highest outliers based on medical and/or prescription costs accounted for $39 \%$ of all costs of participants in the program. Four of these five were on specialty medications unrelated to their diabetes that greatly inflated their costs. The average comparisons were therefore calculated after removing the outliers, consisting of approximately $75-80 \%$ of the program participant population.

\section{Expansion in Pharmacy Services}

Based upon the continued success seen with the pharmacistdelivered diabetes education program, the city expanded their disease management services offered to patients to include cardiovascular management to patients without diabetes. Beginning in 2017, a new curriculum specifically focused on patients with cardiovascular disease was implemented in the pharmacy for all eligible patients. Similar copay waivers were made available to program participants, and the pharmacist completed a certificate training program on Pharmacy-Based Cardiovascular Disease Risk Management offered through APhA. Student pharmacists assisted in the implementation and expansion of these services, added to the diabetes management services that were made available to patients for over ten years at that time.

\section{RESULTS}

Table 1 summarizes patient participation, average lab values, and numbers of student pharmacists trained over the most recent eight years of the program. It also includes the patients participating in the cardiovascular program after its inception in 2017. The pharmacy trained student pharmacists year-round to assist in this chronic care delivery, training 64 students on 6week rotations across the 8-year period. As mentioned, average values for lab measurements were calculated based on quarterly $\mathrm{A} 1 \mathrm{C}$ measurements, blood pressures performed at every visit, and LDL-C values measured on an annual or biannual basis.

Table 2 outlines the financial estimates calculated to measure any impact of the pharmacy disease management programs. As noted, these did not include "outliers", patients who exceeded $\$ 10,000$ in either medical or prescription costs for the year. Data for cost savings on the cardiovascular program are only available for the three years since its inception.

Figure 1 looks specifically at patients enrolled in the pharmacy diabetes program in 2019. Of note, these costs included all patients in the program for 2019, including those determined to be outliers. These patients were compared to published national data estimating costs for patients with diabetes two years earlier in 2017. The same comparison was made between these groups in regards to emergency room visits, while also adding in patients with diabetes utilizing the pharmacy that opted out of the diabetes management program.

These results summarize a program with consistent patient enrollment as a student pharmacist training model, estimate the financial impact these services represent, and present average objective lab measurements on an annual basis.

\section{DISCUSSION}

This manuscript describes a sustained disease management service initiated through a grassroots grant-funded effort that has been maintained for over 14 years. The success of this program is largely due to the backing and support that the city of Colorado Springs has shown by financially supporting the program and the pharmacist time to run it after the grantfunded Ten City Challenge ended. The work of this pharmacist to distinguish her city as one of the top three performers within the program doubtlessly influenced the decision to continue this program for the city employees that the pharmacy serves.

Several components of this program are notable for pharmacies interested in implementing this type of program. Enrollment data show consistent participation of between 93-120 patients annually with the city's diabetes management program. It also showed high participation in the new cardiovascular program as well, averaging right around 100 patients every year since its inception in 2017. Providing a financial incentive to participants 
by waiving medication copays played an essential part in sustaining this consistent, large population of patients. Attrition in any disease management program is well documented, so establishing this incentive to the consumer helps them prioritize the time spent with the pharmacist leading to the documented positive outcomes. This pharmacy was unique in the fact that they had a fixed population of patients who received benefits through the city, and that the pharmacy itself was a closed-door operation, serving only patients that were part of the city's healthcare program. This allowed the pharmacy team to have full access to the patients' medical records, and to maintain the copay incentives such that patients who were not attending education sessions became unenrolled and lost their copay waivers.

Participating patients' average objective lab measurements suggest relative success in managing these patients. $\mathrm{A} 1 \mathrm{C}$ values were measured or collected quarterly, as recommended in the ADA Standards of Care. ${ }^{14}$ While participants' average A1C did not attain the ideal $<7 \%$ goal that is specified for many nonpregnant adult patients who live with diabetes, the averages showed little fluctuation across the eight year time frame and never exceeded $7.4 \%$. Importantly, these averages were calculated across the entire population of patients participating in the program, including those who were considered high risk due to age, advanced complications, or risk of hypoglycemia. In these instances, ADA clinical guidelines recommend a less stringent $A 1 C$ goal of $7.5 \%$ or even $8 \%$, numbers consistently exceeded in the pharmacy program. Averages also included patients newly enrolled into the program, whose $\mathrm{A} 1 \mathrm{C}$ values may have been elevated initially before improving over time. Cardiovascular laboratory measurements for these patients showed similar successes, with average blood pressure measurements consistently reported below the recommended 130/80 $\mathrm{mmHg}$ mark set for diabetes patients at high cardiovascular risk, per ADA guidelines. ${ }^{14}$ Average LDL-C measurements across the entire diabetes population were also attained below the benchmark of less than $100 \mathrm{mg} / \mathrm{dl}$ across all eight years, approaching the more aggressive target of less than $70 \mathrm{mg} / \mathrm{dl}$ that is reserved for those patients with very high cardiovascular risk. Considering the additional cardiovascular program that was added in 2017, those patients' average blood pressure values fell within one point of the defined "normal" benchmark of $120 / 80 \mathrm{mmHg}$ across all three years, with their LDL-C values still falling below the $100 \mathrm{mg} / \mathrm{dl}$ threshold recommended for patients with clinical atherosclerotic cardiovascular disease (ASCVD). ${ }^{16,17}$

Community pharmacy thought leaders clearly believe that value-based payments represent an important future for the practice. In order to approach insurance companies and negotiate payment for services, there must be evidence that pharmacist-delivered care leads to cost savings to the companies. Considering the data from table 2, there was an estimated prescription cost savings associated with the diabetes program every year, with increasing savings occurring annually over the last four years. Similarly, overall medical cost savings were demonstrated every year except one, where the program essentially broke even. As mentioned earlier, outlier patients whose expenses exceeded $\$ 10,000$ annually were not included in these analyses, so this only represented $75-80 \%$ of the patients in the program. The cardiovascular program also demonstrated cost savings on the medical side, although prescription costs actually rose in the second and third year of the program above the estimated inflation rates. This was likely due to two factors: the pharmacist identified a large number of patients who were non-adherent to therapy, and when resolving this increased the overall prescriptions filled annually, and additional therapies were recommended for patients who were not controlled, also contributing to higher costs. It is anticipated that these increased costs should level off and demonstrate savings as the program progresses.

Figure 1, outlining the patients in 2019, showed that those patients participating in the diabetes program demonstrated an estimated total average cost of care (prescription and medical costs) of $\$ 15,506$ per member. Of note, these calculations included the outliers removed from table 2 estimates. This is approximately $\$ 1,250$ per member less expensive when comparing this cost to 2017 published national data for patients with diabetes. ${ }^{18}$ It is reasonably expected that overall healthcare costs rise each year due to inflation, so 2019 national averages are likely even higher. This figure also demonstrated that participants in the pharmacy diabetes program reduced their emergency room admissions by $50 \%$ compared with patients in the same pharmacy who opted out of the program. Again, when comparing the rates of program participants to the national average of diabetes patients two years earlier, rates of emergency room visits were four times lower than the 2017 national average. ${ }^{18}$

This project has limitations. First and foremost, the program was designed and implemented with a focus on clinical care with a goal of improving the health of a population of diabetes patients, and later patients with cardiovascular disease. Since it was not designed for research, drawing definitive conclusions from collected data is not possible. There was no control group to compare individuals who received the care with, and no fixed time points for objective laboratory measurements to be drawn. Baseline labs were not recorded for comparison, and the program had a rolling enrollment, with individuals entering and leaving the program throughout each year. While speculations can be made about the clinical control of these patients based on the lab averages, no direct correlations can be made. The population represented is from one city in the state of Colorado, specifically individuals and their families employed by the city. Lab measurements were provided in aggregate based on program participants, so it is possible that patients who were less successful or did not attain good clinical improvements could have dropped out of the program and would no longer be tracked for their outcomes. The financial calculations are a rough estimate based upon published 
inflation rates, and excluded the high cost outliers. To truly evaluate the financial impact this service had on health care costs, more robust, sophisticated financial calculations should be performed. Emergency room visits were lower in both program participants and those who did not participate, compared with the national average. This suggests that the population studied may already be healthier than the average American. It is noted, however, that participants further reduced their ER visits by $50 \%$ compared with non-participants. The intention with this manuscript is to highlight a sustained pharmacist-based program that has maintained high patient enrollment. Taken as a whole, the continued support that the city shows with these programs, and the continued patient participation strongly suggest the inherent value that these pharmacy services represent.

\section{CONCLUSION}

A community pharmacy serving city employees of Colorado Springs has successfully maintained a robust pharmacistdirected chronic disease management program with around 100 participants for over 14 years. Data from the last eight years highlight its value for training student pharmacists, and average lab measurements suggest consistent control of diabetes and cardiovascular disease. Financial estimates also demonstrate a notable positive impact that the program has made on the overall health care system.

Acknowledgement: The authors would like to acknowledge Maxor National Pharmacy Services and the City of Colorado Springs for their support in this program.

Conflicts of Interest: There are no conflicts of interest or financial interests that the authors or members of their immediate families have in any product or service discussed in the manuscript, including grants (pending or received), employment, gifts, stock holdings or options, honoraria, consultancies, expert testimony, patents and royalties.

This work was designated Not Human Subject Research by the Colorado Institutional Review Board.

\section{REFERENCES}

1. George J, McNamara K, Stewart K. The roles of community pharmacists in cardiovascular disease prevention and management. Australas Med J. 2011;4(5):266-272.

2. Cranor CW, Bunting BA, Christensen DB. The Asheville Project: long-term clinical and economic outcomes of a community pharmacy diabetes care program. J Am Pharm Assoc (Wash). 2003;43(2):173-184.

3. Moore JM, Shartle D, Faudskar L, Matlin OS, Brennan TA. Impact of a patient-centered pharmacy program and intervention in a high-risk group. J Manag Care Pharm 2013;19(3):228-236.

4. Kirkham HS, Clark BL, Paynter J, Lewis GH, Duncan I. The effect of a collaborative pharmacist-hospital care transition program on the likelihood of 30-day readmission. Am J Health Syst Pharm. 2014;71(9):739-745.
5. Nuffer W, McCollum M, Ellis SL, Turner CJ. Further development of pharmacy student-facilitated diabetes management clinics. Am J Pharm Educ. 2012;76(3):Article 50.

6. Shogbon AO, Lundquist LM. Student pharmacists' clinical interventions in advanced pharmacy practice experiences at a community nonteaching hospital. Am J Pharm Educ. 2014;78(3):Article 50.

7. Hata M, Klotz R, Sylvies R, et al. Medication therapy management services provided by student pharmacists. Am J Pharm Educ. 2012;76(3):Article 51.

8. Shepler BM. Cost savings associated with pharmacy student interventions during APPEs. Am J Pharm Educ. 2014;78(4): Article 71.

9. Vande Griend JP, Rodgers M, Nuffer W. Effect of an Advanced Pharmacy Practice Experience on Medication Therapy Management Services in a Centralized Retail Pharmacy Program. J Manag Care Spec Pharm 2017;23(5):561-565.

10. McCollum M, Nuffer W, Ellis SL, Turner CJ. Physician acceptance of pharmacotherapy recommendations made by pharmacy students in a rural pharmacy-based diabetes care and education clinic. Am J Pharm Educ. 2009;73(2):Article 24.

11. Rx Safe. Declining pharmacy reimbursement: the facts. https://rxsafe.com/declining-reimbursement-the-facts/. Accessed November 23rd, 2020.

12. Drug Channels. Pharmacy DIR fees hit a record $\$ 9$ billion in 2019- that's $18 \%$ of total Medicare D rebates. https://www.drugchannels.net/2020/02/pharmacy-dirfees-hit-record-9-billion.html. Accessed November $23^{\text {rd }}$, 2020.

13. Fera T, Bluml BM, Ellis WM. Diabetes Ten City Challenge: final economic and clinical results. J Am Pharm Assoc 2009;49(3):383-391.

14. American Diabetes Assocation. American Diabetes Association Standards of Medical Care in Diabetes-2020. Diabetes Care. 2020;Vol. 43 Sup. 1.

15. Segal Reports and Surveys. Health care trends in 2020: Health plan cost trend survey. www.segalco.com/consulting-insights/healthcare-trends2020. Accessed November 23rd, 2020.

16. Whelton PK, Carey RM, Aronow WS, et al. 2017 ACC/AHA/AAPA/ABC/ACPM/AGS/APhA/ASH/ASPC/NMA/P CNA Guideline for the Prevention, Detection, Evaluation, and Management of High Blood Pressure in Adults: Executive Summary: A Report of the American College of Cardiology/American Heart Association Task Force on Clinical Practice Guidelines. Hypertension. 2018;71(6):12691324.

17. Grundy SM, Stone NJ, Bailey AL, et al. 2018 AHA/ACC/AACVPR/AAPA/ABC/ACPM/ADA/AGS/APhA/ASPC /NLA/PCNA Guideline on the Management of Blood Cholesterol: A Report of the American College of Cardiology/American Heart Association Task Force on Clinical Practice Guidelines. Circulation. 2019;139(25):e1082-e1143.

18. American Diabetes Association. Economic Costs of Diabetes in the U.S. in 2017. Diabetes Care. 2018;41(5):917-928. 
Table 1. Summary of patient enrollment, student pharmacists trained, and average objective lab measurements over the past eight years of the pharmacy services

\begin{tabular}{|c|c|c|c|c|c|c|c|}
\hline $\begin{array}{c}\text { Year of } \\
\text { Program }\end{array}$ & $\begin{array}{c}\text { Service(s) } \\
\text { offered }\end{array}$ & $\begin{array}{c}\text { \# of } \\
\text { patients } \\
\text { enrolled }\end{array}$ & $\begin{array}{c}\text { \# of } \\
\text { students } \\
\text { trained }\end{array}$ & $\begin{array}{c}\text { Average } \\
\text { A1C }\end{array}$ & $\begin{array}{c}\text { Average } \\
\text { systolic BP } \\
\text { (mmHg) }\end{array}$ & $\begin{array}{c}\text { Average } \\
\text { diastolic } \\
\text { BP } \\
\text { (mmHg) }\end{array}$ & $\begin{array}{c}\text { Average } \\
\text { LDL-C } \\
\text { (mg/dl) }\end{array}$ \\
\hline 2012 & DM & 108 & 8 & $7.2 \%$ & 119 & 74 & 85 \\
\hline 2013 & DM & 120 & 8 & $7.4 \%$ & 120 & 74 & 85 \\
\hline 2014 & DM & 110 & 8 & $7.2 \%$ & 120 & 77 & 88 \\
\hline 2015 & DM & 93 & 8 & $7.3 \%$ & 122 & 77 & 79 \\
\hline 2016 & DM & 98 & 8 & $7.2 \%$ & 121 & 78 & 100 \\
\hline 2017 & DM, CV & 104,97 & 8 & $7.2 \%$ & 121,120 & 76,76 & 83,88 \\
\hline 2018 & DM, CV & 99,101 & 8 & $7.2 \%$ & 121,121 & 80,77 & 91,90 \\
\hline 2019 & DM, CV & 104,98 & 8 & $7.2 \%$ & 116,119 & 76,77 & 85,89 \\
\hline
\end{tabular}

Abbreviations: $\mathrm{DM}=$ diabetes mellitus, $\mathrm{CV}=$ cardiovascular disease, $\#=$ number, $\mathrm{A} 1 \mathrm{C}=$ hemoglobin $\mathrm{A1C}$, $\mathrm{BP}=$ blood pressure, $\mathrm{mmHg}=$ millimeters of mercury, $\mathrm{mg}=$ =milligram, $\mathrm{dl}=$ deciliter,

LDL-C= low-density lipoprotein-cholesterol

Table 2. Estimated financial savings per member/per year associated with pharmacy program over the past eight years*

\begin{tabular}{|c|c|c|c|c|}
\hline $\begin{array}{c}\text { Year of } \\
\text { Program }\end{array}$ & $\begin{array}{c}\text { Estimated } \\
\text { prescription cost } \\
\text { changes PMPY- } \\
\text { diabetes program }\end{array}$ & $\begin{array}{c}\text { Estimated } \\
\text { prescription cost } \\
\text { changes PMPY- CV } \\
\text { program }\end{array}$ & $\begin{array}{c}\text { Estimated medical cost } \\
\text { changes PMPY- diabetes } \\
\text { program }\end{array}$ & $\begin{array}{c}\text { Estimated medical cost } \\
\text { changes PMPY- CV } \\
\text { program }\end{array}$ \\
\hline 2012 & $-\$ 961$ & & $-\$ 739$ & \multirow{2}{*}{} \\
\hline 2013 & $-\$ 1,400$ & & $-\$ 1,027$ & \\
\hline 2014 & $-\$ 1,164$ & & $-\$ 1,439$ & \\
\hline 2015 & $-\$ 1,449$ & & $-\$ 1,142$ & \\
\hline 2016 & $-\$ 1,136$ & & $+\$ 9$ & $-\$ 862$ \\
\hline 2017 & $-\$ 2,835$ & $-\$ 1,750$ & $-\$ 320$ & $-\$ 961$ \\
\hline 2018 & $-\$ 3,387$ & $+\$ 1,746$ & $-\$ 860$ & $-\$ 163$ \\
\hline 2019 & $-\$ 4,222$ & $+\$ 2,628$ & $-\$ 1,018$ & \\
& & & & \\
& & & &
\end{tabular}

Abbreviations: $\mathrm{PMPY}=$ per member/per year, $\mathrm{CV}=$ cardiovascular disease

*Financial estimates excluded outliers, defined as having $>\$ 10,000$ in medical or prescription costs in a year 
Figure 1. Cost and emergency room comparison for patients with diabetes using the City Employee pharmacy compared with 2017 national averages. ${ }^{18}$
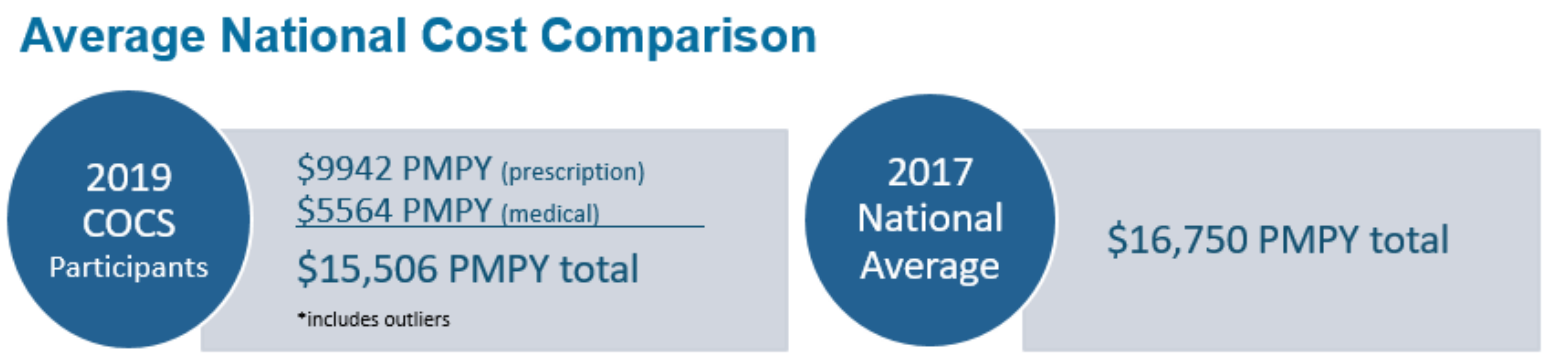

\section{Average National ER Visits Comparison}

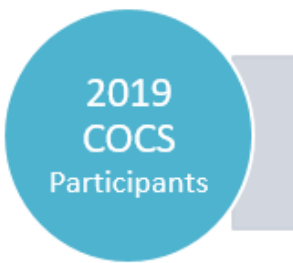

0.16 average visits per participant per year

0.30 average ER visit per Non-participant per year

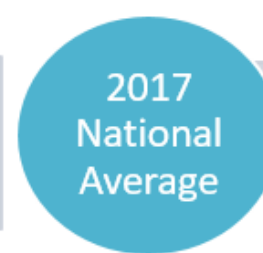

0.68 average visits per person with diagnosed diabetes per year

Abbreviations: $\mathrm{COCS}=$ city of Colorado Springs, $\mathrm{PMPY}=$ per member per year, $\mathrm{ER}=$ emergency room 